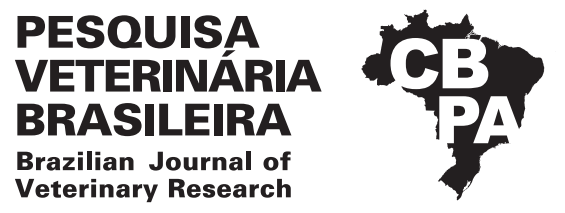

Pesq. Vet. Bras. 38(10):1999-2005, outubro 2018 DOI: 10.1590/1678-5150-PVB-5288

Artigo Original

ISSN 0100-736X (Print)

ISSN 1678-5150 (Online)

\title{
Morfologia do órgão vomeronasal da paca (Cuniculus paca Linnaeus, 1766) ${ }^{1}$
}

\author{
Mariana C.S. Figueiredo ${ }^{2}$, Leonardo M. Leal ${ }^{3}$, Fabrício S. Oliveira², \\ Leandro L. Martins ${ }^{4}$, Sergio P. Garcia Filho ${ }^{5}$, Marcia R.F. Machado ${ }^{2}$ \\ e Tais H.C. Sasahara ${ }^{6 *}$
}

\begin{abstract}
Figueiredo M.C.S., Leal L.M., Oliveira F.S., Martins L.L., Garcia Filho S.P., Machado M.R.F. \& Sasahara T.H.C. 2018. [Morphology of the paca vomeronasal organ (Cuniculus paca Linnaeus, 1766).] Morfologia do órgão vomeronasal da paca (Cuniculus paca Linnaeus, 1766). Pesquisa Veterinária Brasileira 38(10):1999-2005. Faculdade de Ciências Agrárias e Veterinárias, Universidade Estadual Paulista, Via de acesso Prof. Paulo Donato Castellane s/n, SP 14884-900, Jaboticabal, Brazil. E-mail: tsasahara@gmail.com

The vomeronasal organ is a chemical receptor capable of detecting pheromones and for this reason is involved in reproductive, social and defense behaviors. The breeding of pacas has been highlighted in commercialization of meat and for conservation and research purposes, as an experimental model. Regarding the necessity of detailing the morphology of the secondary olfactory system, the vomeronasal system, the macroscopic anatomy, microscopic anatomy and topography of the vomeronasal organ (OVN) was described. Five adult pacas, from the wild animal Sector at FCAV, Unesp, Jaboticabal, SP were used. After the euthanasia, it was perfused $10 \%$ formaldehyde solution by ascendent aorta. The OVN was dissected for topographic and anatomical descriptions. Then, it was included in plastic paraffin. Five micrometres sections were collected and stained with hematoxylin and eosin. The OVN is located on the floor of the nasal cavity in both sides of the base of nasal septum and it was related to the vomer, palatine process of the premaxilar and maxilar bones. In rostral aspect, it has a communication with the oral cavity and with the incisive papilla. It is a paired organ with irregular surface. In transversal section is slight elliptical with brownish colour similar to a sponge full of blood vessels. By light microscopy, it was observed the vomeronasal cartilage. The organ is covered with non-sensorial and neurossensorial epithelia.
\end{abstract}

INDEX TERMS: Anatomy, histology, Jacobson's organ, olfactory system, Cuniculus paca.

\footnotetext{
${ }^{1}$ Recebido em 20 de outubro de 2017.

Aceito para publicação em 13 de dezembro de 2017.

${ }^{2}$ Faculdade de Ciências Agrárias e Veterinárias (FCAV), Universidade Estadual Paulista (Unesp), Campus Jaboticabal, Via de acesso Prof. Paulo Donato Castellane s/n, Jaboticabal, SP 14884-900, Brasil.

${ }^{3}$ Departamento de Medicina Veterinária, Faculdade Ingá (Uningá), Rodovia PR-317 no 6114, Maringá, PR 87035-510, Brasil.

${ }^{4}$ Departamento de Medicina Veterinária, Universidade Estadual de Maringá (UEM), Campus Umuarama, Estrada da Paca s/n, Bairro São Cristóvão, Umuarama, PR 87507-190, Brasil.

${ }^{5}$ Departamento de Medicina Veterinária, Faculdade Ingá (Uningá), Rodovia PR-317 no 6114, Maringá, PR 87035-510.

${ }^{6}$ Universidade de Franca (Unifran), Av. Dr. Armando Salles Oliveira 201, Pq. Universitário, Franca, SP 14404-600, Brasil. *Autor para correspondência: tsasahara@gmail.com
}

RESUMO.- 0 órgão vomeronasal é um receptor químico capaz de detectar feromônios e por essa razão está envolvido nos comportamentos reprodutivos, sociais e de defesa. A reprodução de pacas tem se destacado na área de comercialização de carne e para fins conservacionistas e de pesquisa, como modelo experimental. Diante da necessidade do detalhamento da morfologia do sistema olfatório secundário, o sistema vomeronasal, foi descrita a anatomia macroscópica, anatomia microscópica e topografia do órgão vomeronasal (OVN) da paca (Cuniculus paca). Foram utilizadas cinco pacas adultas do Setor de Animais Silvestres da FCAV, UNESP, Jaboticabal-SP. Após a eutanásia dos animais, a solução fixadora de formaldeído 10\% em tampão fosfato de sódio (PBS) foi perfundida sistemicamente (via aorta ascendente). Mediante dissecação, o OVN foi 
localizado e individualizado para a descrição topográfica e anatômica. Posteriormente, foi isolado e incluído em parafina plástica. Cortes de cinco micrômetros foram corados com Hematoxilina-Eosina. O OVN encontra-se no assoalho da cavidade nasal em ambos os lados da base do septo nasal e está relacionado com o osso vômer, processos palatinos dos ossos pré-maxilar e maxilar. Rostralmente, comunica-se com a cavidade oral estabelecendo relação com a papila incisiva. É um órgão par com superfície irregular, levemente elíptico em secção transversal, apresentando coloração amarronzada repleta de vasos sanguíneos. À microscopia de luz, notou-se presença da cartilagem vomeronasal. 0 órgão é revestido por um epitélio não sensorial e neurossensorial.

TERMOS DE INDEXAÇÃO: Anatomia, histologia, órgão de Jacobson, sistema olfatório, Cuniculus paca.

\section{INTRODUÇ̃̃OO}

A paca é o segundo maior roedor da fauna brasileira (Mondolfi 1972, Matamoros 1982) alcançando $80 \mathrm{~cm}$ de comprimento corpóreo e $12 \mathrm{~kg}$ de peso (Organización de las Naciones Unidas para la Agricultura y la Alimentación 1995, Pachaly et al. 2001). Com tempo médio de sobrevida de 16 anos, essa espécie de roedor está presente em grande parte do território brasileiro e distribui-se geograficamente desde o sudeste do México até o sul do Paraguai e norte da Argentina, em altitudes de até 3.000 metros (Eisenberg \& Redford 1999, Lange \& Schmidt 2007, Queirolo et al. 2008). Alimenta-se de frutas, mas pode consumir outros vegetais e até insetos em períodos de escassez alimentar (Dubost \& Henry 2006).

Este animal tem sido utilizado para o consumo humano e o Brasil constitui um dos países com diversos criatórios autorizados para este fim (Fiedler 1990, Mockrin et al. 2005). Sua importância, além da comercial como fonte proteica, pode também tomar âmbito da ciência, pois a paca apresenta características como: tamanho adequado, ampla distribuição geográfica, adaptação a ambientes variados, nutrição variada, entre outras, que atendem as condições atribuídas a um modelo animal experimental (Santos 2006).

0 estudo da anatomia macroscópica é um instrumento de importância essencial para a descrição de espécies e, consequentemente, para fazer a comparação entre elas. As descrições são relevantes, dentre outros motivos, para destacar as semelhanças e diferenças morfológicas (Aversi-Ferreira et al. 2006). Descrições anatômicas contribuem para compor o acervo teórico sobre as espécies e para o enriquecimento das aplicações na clínica veterinária, na terapêutica e em programas conservacionistas (Aversi-Ferreira et al. 2005, Vavuk 2012).

0 odor é detectado, nos mamíferos, por dois sistemas; o sistema olfatório principal e o sistema vomeronasal, este último também considerado um sistema olfatório secundário. 0 órgão vomeronasal foi descrito, pela primeira vez, em 1813 pelo anatomista dinamarquês Ludvig Jacobson (Mucignat-Caretta, 2010). Este órgão é um receptor químico do sistema vomeronasal, envolvido na detecção de feromônios e apresenta relação com os comportamentos reprodutivos, sociais e de defesa (Roslinski et al. 2000, Elgayar et al. 2017). Nos mamíferos, está localizado na base do septo do osso vômer, apresentando epitélio sensorial e um mecanismo semelhante a uma bomba que banha o órgão com muco (Mucignat-Caretta,
2010). Neste contexto, a descrição da anatomia macroscópica, microscópica e topografia do órgão vomeronasal da paca é potencialmente relevante porque será descrito pela primeira vez neste roedor. Os resultados certamente irão contribuir para o enriquecimento dos estudos da morfologia comparativa nos roedores silvestres e em outros mamíferos, bem como para elucidar as funções do OVN.

\section{MATERIAL E MÉTODOS}

Foram utilizadas cinco pacas (Cuniculus paca) adultas, machos e fêmeas, pesando entre cinco e $10 \mathrm{~kg}$ oriundas do plantel de pacas do setor de Animais Silvestres da FCAV, Unesp-Jaboticabal, SP, que é registrado no Instituto Brasileiro do Meio Ambiente e dos Recursos Naturais Renováveis-IBAMA, como criatório de espécimes da fauna brasileira para fins científicos (Cadastro de registro 482508), SISBIO no 45757-1.

Para a eutanásia, os animais foram primeiramente sedados com meperidina $(3 \mathrm{mg} / \mathrm{kg})$ associada a midazolan $(1 \mathrm{mg} / \mathrm{kg})$ via intramuscular e, em seguida, anestesiados com quetamina $(25 \mathrm{mg} / \mathrm{kg})$ e xilazina $(0,5 \mathrm{mg} / \mathrm{Kg})$ também via intramuscular. Por fim, injeção intracardíaca de cloreto de potássio 19,1\%, dose-efeito até a parada cardiorrespiratória (Leal et al. 2014).

Constatado a morte do animal, a cavidade torácica foi aberta e uma cânula foi inserida no ventrículo cardíaco esquerdo e solução de fosfato salino tamponado (PBS) contendo $2 \%$ de heparina e $0,1 \%$ de nitrato de sódio foi perfundida via aorta cranial para a lavagem do sistema vascular. Para que o sistema fosse lavado adequadamente, uma pequena abertura foi feita na aurícula direita para permitir o extravasamento de líquido.

A seguir, a solução fixadora de formaldeído 10\% em tampão fosfato de sódio (PBS) foi perfundida sistemicamente (via aorta ascendente). Para promover uma melhor fixação do órgão vomeronasal (OVN), foi realizada uma perfusão complementar via artéria carótida comum.

Estudo macroscópico. Após a fixação do animal, a cabeça foi removida e um corte mediano foi realizado por meio de serra de fita elétrica para expor as estruturas da cabeça. 0 OVN foi localizado, dissecado e fotodocumentado para a descrição topográfica e anatômica.

Estudo microscópico. Em sequência ao estudo macroscópico, o OVN foi coletado e armazenado em solução tamponada de formaldeído $10 \%$ por 24 horas a $4^{\circ} \mathrm{C}$. O OVN foi seccionado e os fragmentos incluídos em parafina plástica (Histosec-Merck) mediante realização de rotina histológica convencional. A microtomia foi realizada em micrótomo automático (Leica-RM2155), com auxílio de navalhas descartáveis. Cortes de cinco micrômetros $(\mu \mathrm{m})$ foram corados com hematoxilina-eosina (HE). As lâminas foram observadas em microscópio de luz (Leica DM 5000B) e as imagens foram capturadas com câmera digital (Leica DFC 300FX) para a descrição histológica.

\section{RESULTADOS}

\section{Descrição topográfica do órgão vomeronasal}

Situa-se no assoalho da cavidade nasal em ambos os lados da base do septo nasal e se encontra relacionado com o osso vômer, processos palatinos dos ossos pré-maxilar e maxilar. O OVN, bem como o osso vômer, são observáveis pelo forame incisivo (Fig.1). Rostralmente, comunica-se com a cavidade oral estabelecendo relação com a papila incisiva. A comunicação com cavidade nasal se dá pela sutura do osso vômer. Caudalmente, o órgão vomeronasal se apoia no palato duro e termina em fundo cego (Fig. 2A,B). 


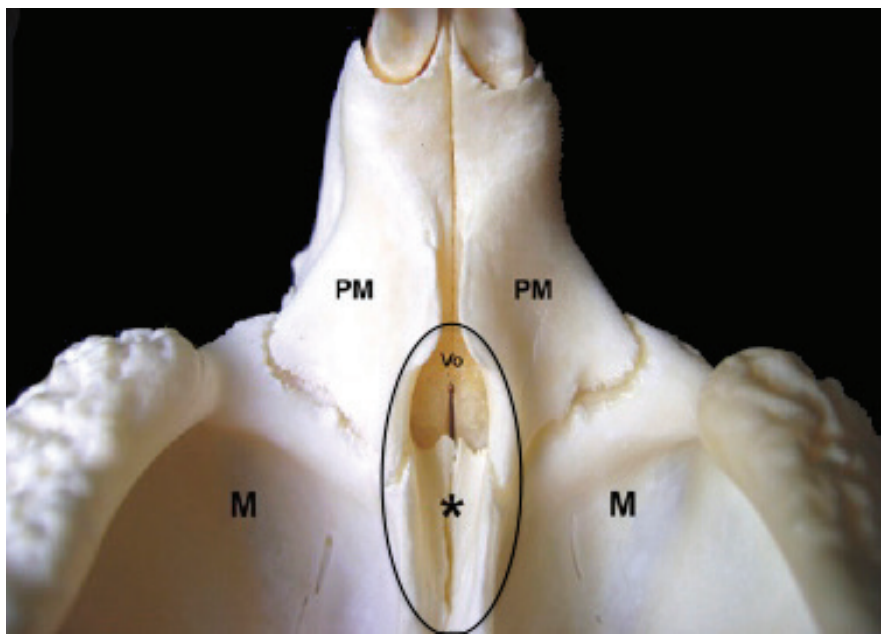

Fig.1. Vista ventral do crânio da paca, evidenciando a localização do OVN $(*)$. Osso pré-maxilar (PM), osso maxilar (M), osso vômer (Vo). O Vo e OVN são observáveis no forame incisivo (círculo). Barra $=0,5 \mathrm{~cm}$.

\section{Descrição macroscópica do órgão vomeronasal}

O órgão vomeronasal da paca é par, com superfície irregular, levemente elíptico em secção transversal, medindo $30 \mathrm{~mm}$ de comprimento e $7 \mathrm{~mm}$ de largura, apresenta coloração amarronzada de aspecto semelhante a uma esponja, repleto de vasos sanguíneos (Fig.2A,B).

\section{Descrição microscópica do órgão vomeronasal}

O órgão vomeronasal (OVN) da paca é formado por um ducto central circundado por uma lâmina de cartilagem hialina, a cartilagem vomeronasal. Medialmente à lâmina cartilaginosa, encontra-se tecido conjuntivo repleto de vasos sanguíneos (Fig.3B). O lume do OVN é revestido por um epitélio não sensorial, pseudoestratificado ciliado e por um epitélio neurossensorial, pseudoestratificado. 0 epitélio não sensorial encontra-se lateralmente e o epitélio neurossensorial, medialmente (Fig.3A). 0 epitélio neurossensorial é formado pelas células basais, pelas células sensoriais e pelas células de suporte. Estas células estão dispostas em camadas. As mais centrais, próximas ao lume, são as células de suporte. Na região intermediária estão as células sensoriais, que apresentam núcleo maior e mais claro e na periferia são encontradas as células basais, em contato com o tecido conjuntivo e próximas aos vasos sanguíneos (Fig.3C). 0 epitélio não sensorial é formado por um epitélio colunar pseudoestratificado ciliado (Fig.3D).

No epitélio neurossensorial do OVN da paca observou-se a formação de estruturas em forma de $\mathrm{U}$, ao corte longitudinal, cujo interior possui cílios e apresenta abertura voltada para o lume (Fig.3D). No tecido conjuntivo há a presença de capilares que se distribuem majoritariamente na base destas estruturas (Fig.4).

\section{DISCUSSÃO}

O órgão vomeronasal da paca, assim como dos demais roedores, é um órgão par, de formato elíptico, delgado em secção transversal. Seu tamanho é de aproximadamente $30 \mathrm{~mm}$ de comprimento e $7 \mathrm{~mm}$ de largura; porém varia de tamanho longitudinalmente, tendo a porção caudal mais estreita, terminando em fundo cego. De acordo com Halpern
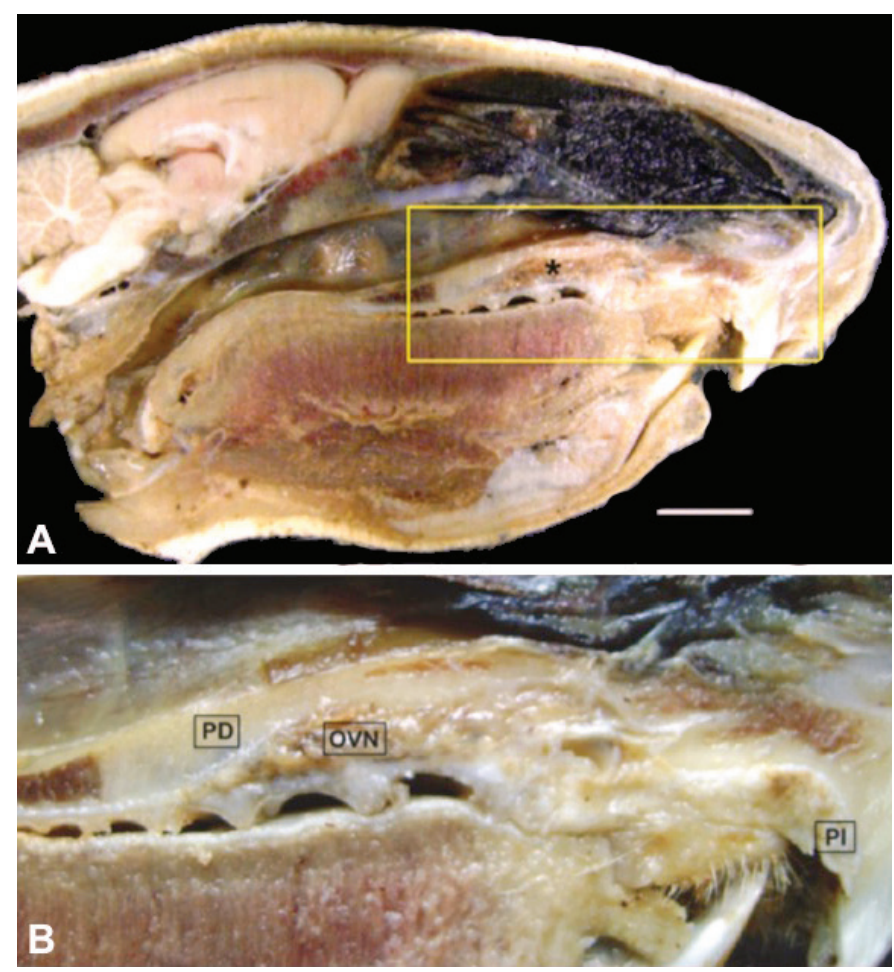

Fig.2. (A) Corte mediano da cabeça da paca. Em destaque, região do órgão vomeronasal $(*)$. Barra $=2 \mathrm{~cm}$. (B). Órgão vomeronasal (OVN), estabelecendo caudalmente contato com o palato duro (PD) e rostralmente com a papila incisiva (PI).

(1987), na maioria dos mamíferos, o OVN é um tubo alongado, semelhante a um cigarro, de fundo cego no aspecto caudal e frequentemente, no aspecto rostral, apresenta comunicação com o ducto nasopalatino. Em cavalos, notou-se que o ducto incisivo apresenta-se em fundo cego rostralmente e não faz contato com a papila incisiva (Salazar et al. 1995).

A dimensão do OVN em rato foi de 6-7 $\mathrm{mm}$ de comprimento e de 1,2-1,5mm de largura (Vaccarezza et al. 1981) e de $7 \mathrm{~mm}$ de comprimento no hamster (Taniguchi \& Mochizuki 1983). Já em cervo, o comprimento foi de aproximadamente $80 \mathrm{~mm}$, o que foi igualmente observado no cão (Salazar et al. 2013, Park et al. 2014). Ardalani et al. (2001) relatou, em bubalinos, o comprimento de aproximadamente $19 \mathrm{~cm}$ e Lindsay et al. (1978), em cavalos e burros, o comprimento de $12-15 \mathrm{~cm}$. Avaliações alométricas do OVN de um pequeno marsupial australiano, o Antechinus subtropicus, foram realizadas por Aland et al. (2016). Estes autores concluíram que o comprimento total do OVN correlaciona-se positivamente com o tamanho do animal.

Trabalhos inferem que a redução no tamanho do OVN, bem como a redução de seus componentes ou mesmo a sua ausência, como visto em mamíferos marinhos, morcegos e alguns primatas, pode indicar uma perda de função e, portanto, a falta da importância desse sentido nesses animais (Halpern 1987, Bhatnagar \& Meisami 1998). Já um OVN maior, contendo elementos sensoriais mais evidentes, a presença de cápsula óssea ou cartilaginosa e seios venosos, como encontrado nos ratos e camundongos indicam a importância desse órgão para estas espécies (Dawley \& Crowder 1995). 

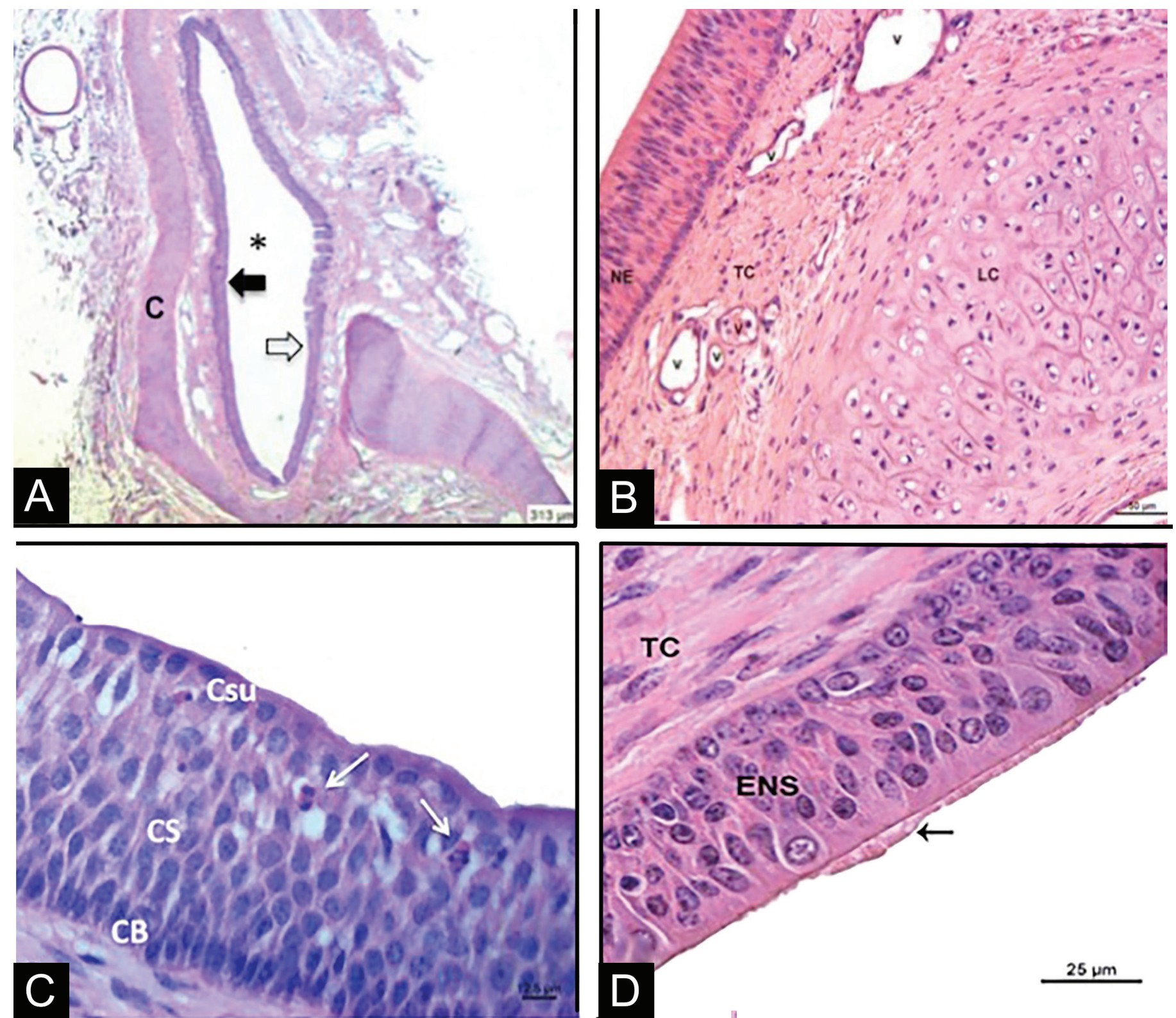

Fig.3. (A) Órgão vomeronasal (OVN) da paca. Secção transversal do OVN. Lúmen do ducto do OVN (*), envolto por epitélio neurossensorial (seta preta), epitélio não sensorial (seta branca) e lâmina de cartilagem (C). HE, barra $=313 \mu$ m. (B) Epitélio pseudoestratificado neurossensorial (NE), tecido conjuntivo (TC), repleto de vasos sanguíneos (v) e lâmina de cartilagem (LC). HE, barra = 50 $\mu \mathrm{m}$. (C) Epitélio pseudoestratificado formado por células basais (CB), células sensoriais (CS) e células de suporte (Csu). Leucócitos (seta), veia (v). HE, barra = 12,5 $\mu \mathrm{m}$. (D) Epitélio não sensorial (ENS). Cílios (seta). Tecido conjuntivo (TC). HE, barra = 25 $\mu \mathrm{m}$.

O OVN na paca apresenta cor amarronzada de aspecto semelhante a uma esponja, repleto de vasos sanguíneos. Essa característica possivelmente está relacionada à função de bombear líquidos e gases para o ducto vomeronasal, como observado em hamster por Meredith (1994). Os vasos sanguíneos do OVN estão sob o comando do sistema nervoso autônomo, assim são capazes de dilatar ou contrair, aumentando ou diminuindo o tamanho do lume do órgão para facilitar a entrada ou saída de fluido do seu interior (Eccles 1982, Meredith et al. 1980).

Quanto à topografia, o OVN situa-se na porção rostral do palato duro em contato com o assoalho da cavidade nasal e com o osso vômer em ambos os lados da base do septo nasal, assim como descrito nos demais mamíferos (Barone et al. 1966, Taniguchi \& Mochizuki 1982, Salazar et al. 1996, Keverne 1999, Salazar et al. 2013, Park et al. 2014). Na paca, a comunicação com a cavidade oral se dá por meio da papila incisiva e a comunicação com a cavidade nasal parece ser estabelecida por meio da sutura intervomeriana, já que a porção rostral do OVN está em contato com esta sutura e a mesma faz contato dorsalmente com a cavidade nasal. A sutura intervomeriana foi observada também em outros roedores, como no preá (Cavia aperea) e em algumas espécies do gênero Proechimys, que incluem roedores caviomorfos 


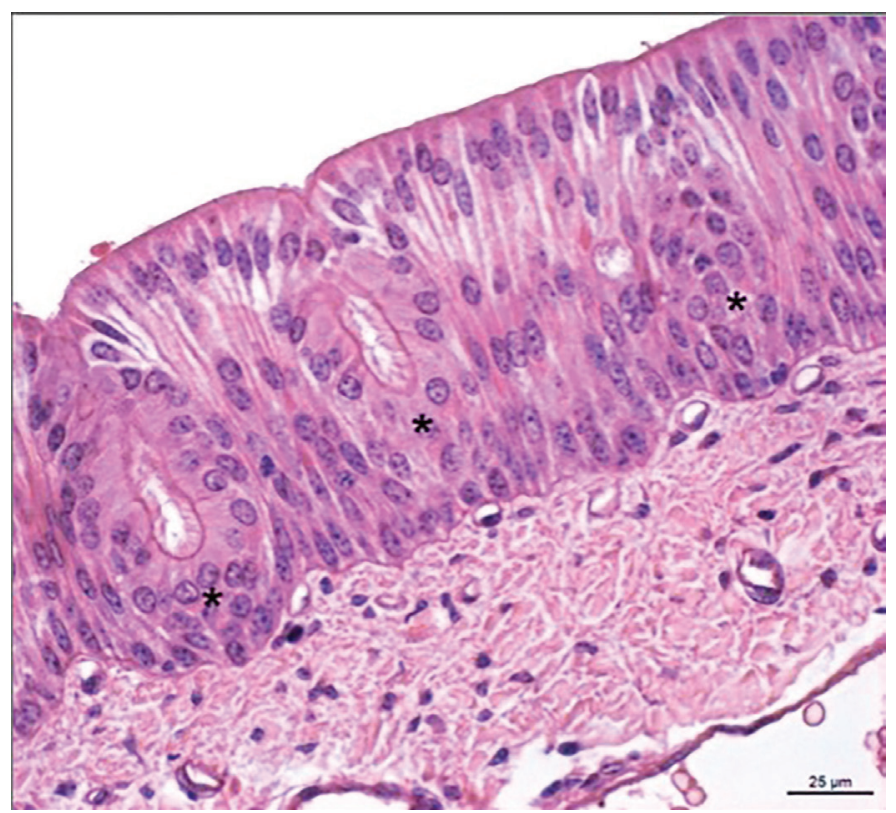

Fig.4. Epitélio com estruturas em forma de U, cujo interior apresenta cílios ( ${ }^{*}$ ). Tecido conjuntivo com capilares (TC). HE, barra $=25 \mu \mathrm{m}$.

encontrados na Caatinga brasileira (Rocha 1995, Cherem \& Ferigolo 2012). No gato, o OVN estabelece a comunicação entre a cavidade nasal e a cavidade oral por meio da fissura palatina (Salazar et al. 1996). Em roedores, como o rato, o lume do órgão vomeronasal comunica com a cavidade nasal através de um forame na extremidade rostral do órgão (Vaccarezza et al. 1981). Nos coelhos, o OVN desemboca na cavidade nasal através do canal nasopalatino enquanto em carnívoros, ungulados, insetívoros e primatas este órgão abre-se na cavidade oral através do canal incisivo (Barone et al. 1966, Keverne 1999).

Quanto à avaliação da anatomia microscópica, na paca foi encontrada a cartilagem vomeronasal, como no cão, gato, vaca, cabra, ovelha, porco e cavalo (Salazar et al. 2000, Salazar et al. 2004, Salazar et al. 2007). A cartilagem vomeronasal pode envolver total ou parcialmemente as estruturas do OVN nos mamíferos, desempenhando papel de proteção (Salazar et al. 1995). No rato, camundongo e hamster foi descrita a presença de uma cápsula óssea (Taniguchi \& Mochizuki 1983). Em coelhos, Taniguchi \& Mochizuki (1983) relatam a ausência da cápsula óssea; porém, Grondona (2012) descreve uma fina cápsula óssea ao redor da cartilagem vomeronasal. Na paca, a cartilagem vomeronasal circunda parcialmente um ducto central, como no cão e no ferret (Weiler et al. 1999, Salazar et al. 2013) o qual está rodeado de tecido conjuntivo com intensa vascularização. Os vasos localizam-se no tecido conjuntivo, especialmente no epitélio neurossensorial, como o observado por Grondona (2012). Glândulas túbulo acinosas no tecido conjuntivo do OVN foram descritas no cão e camundongo (Salazar et al. 2013) porém, não foram encontradas na paca.

O lume elíptico é recoberto por epitélios neurossensorial e não sensorial, assim como nos demais mamíferos (Holy etal. 2000, Curtis et al. 2001). Em corte transversal, conforme descrito por outros autores, lateralmente está o epitélio não sensorial e medialmente, o epitélio neurossensorial (Taniguchi \& Mochizuki 1983, Mucignat-Caretta 2010) A porção não sensorial é composta por epitélio pseudoestratificado ciliado. 0 epitélio neurossensorial é composto por camadas e três tipos de células: a primeira camada, mais superficial e próxima ao lume é formada pelas células de suporte alongadas com núcleos ovais escuros; a segunda é composta por várias camadas de células sensoriais claras com núcleos arredondados e maiores; e em contato com o tecido conjuntivo, a terceira camada, formada por células basais. A mesma descrição foi realizada por Taniguchi \& Mochizuki (1983), Salazar et al. (1996), Salazar et al. (2013).

No epitélio neurossensorial do OVN da paca, observamos uma estrutura, que ao corte longitudinal, apresenta a forma da letra U, com abertura voltada para o lume em cujo interior há cílios. Não encontramos na literatura a descrição de tal estrutura. Acredita-se que estes cílios possam facilitar a condução do estímulo químico aos receptores do OVN, porém estudos mais detalhados serão necessários para melhor descrever esta estrutura do ponto de vista estrutural e funcional.

\section{CONCLUSÕES}

A topografia do órgão vomeronasal da paca assemelha-se à descrita para outros mamíferos.

À descrição macroscópica, o OVN da paca apresenta tamanho proporcional ao comparar a de outros roedores, como o rato e o hamster.

A sutura intervomeriana parece ser o meio de comunicação entre as cavidades oral e nasal.

A paca apresenta a cartilagem vomeronasal e não uma cápsula óssea como reportada em outros roedores.

À microscopia, as células do epitélio não sensorial e neurossensorial são semelhantes às descritas para roedores, coelho, cão e gato.

No epitélio neurossensorial, no entanto, a paca apresenta estrutura típica em forma da letra U, cujo interior apresenta cílios.

Agradecimentos.- À Fundação de Amparo à Pesquisa do Estado de São Paulo (FAPESP, processo 2014/08055-1), pela concessão da bolsa de iniciação científica.

\section{REFERÊNCIAS}

Aland R.C., Gosden E. \& Bradley A.J. 2016. Seasonal morphometry of the vomeronasal organ in the marsupial mouse, Antechinus subtropicus. J. Morphol. 277(11):1517-1530.<http://dx.doi.org/10.1002/jmor.20593> $<$ PMid:27641160>

Ardalani G.H., Sadrkhanloo R. \& Abbasi M. 2001. Anatomy and histology of vomeronasal organ of buffalo. J. Fac. Vet. Med. Univ. Tehran 55:5-11.

Aversi-Ferreira T.A., Mata J.R., Paula J.P. \& Silva M.S.L. 2006. Anatomia comparativa entre os músculos extensores do antebraço de Cebus libdinosus com humanos e outros primatas. Revta Eletrôn. Farm. 3(2):13-15.

Aversi-Ferreira T.A., Lima-Silva M.S., Paula J.P., Gouvêa-Silva L.F. \& Silva N.P. 2005. Anatomia comparativa dos nervos do braço de Cebus apella. Descrição do músculo dorsoepitroclear. Acta Scientiarum 27(3):291-296.

Barone R., Lombard M. \& Morand M. 1966. Organe de Jacobson, nerf vomeronasal et nerf terminal du chien. Bull. Soc. Sci .Vet., Lyon, 68(3):257-270.

Bhatnagar K.P. \& Meisami E. 1998. Vomeronasal organ in bats and primates: Extremes of structural variability and its phylogenetic implications. Microsc. Res. Tech. 43(6):465-475. <http://dx.doi.org/10.1002/(SICI)10970029(19981215)43:6<465::AID-JEMT1>3.0.CO;2-1><PMid:9880162> 
Cherem J.J. \& Ferigolo J. 2012. Descrição do sincrânio de Cavia aperea (Rodentia, Caviidae) e comparação com as demais espécies do gênero no Brasil. Papéis Avulsos Zool. 52(3):21-50.

Curtis J.T., Liu Y. \& Wang Z. 2001. Lesion of the vomeronasal organ disrupt mating-induced pair bonding in female prairie voles Microtus ochrogaster. Brain Res. 901(1/2):167-174. <http://dx.doi.org/10.1016/S00068993(01)02343-5><PMid:11368964>

Dawley E.M. \& Crowder J.1995. Sexual and seasonal differences in the vomeronasal epithelium of the red-backed salamander (Plethodon cinereus). J. Comp. Neurol. 359(3):382-390. <http://dx.doi.org/10.1002/cne.903590303> $<$ PMid:7499536>

Dubost G. \& Henry 0. 2006. Comparison of diets of the acouchy, agouti and paca, the three largest terrestrial rodents of French Guianan forests. J. Trop. Ecol.22(06):641-651. <http://dx.doi.org/10.1017/S0266467406003440>

Eccles R. 1982. Autonomic innervation of the vomeronasal organ of the cat. Physiol. Behav. 28(6):1011-1015. <http://dx.doi.org/10.1016/00319384(82)90168-8> <PMid:7111443>

Eisenberg J.F. \& Redford K.H. 1999. Mammals of the Neotropics: the Central Neotropics: Ecuador, Peru, Bolivia, Brazil. 3th ed. University of Chicago, Chicago. 609p.

Elgayar S.A.M., Saad-Eldin H.M. \& Haussein O.A. 2017. Morphology of cat vomeronasal organ non-sensory epithelium during postnatal development. Anat. Cell Biol. 50(1):17-25. <http://dx.doi.org/10.5115/acb.2017.50.1.17> <PMid:28417051>

Fiedler L.A. 1990. Rodents as a food source, p.148-155. In: Davis L.R \& Marsh R.E. (Eds). Vertebrate Pest Conference. Proceedings Collection, University of California Press, Davis.

Grondona K.E.B. 2012. Morfometria do órgão vomeronasal e do testículo, comportamento sexual de coelhos e perfis de testosterona e androstenediona após cauterização do ducto incisivo, Viçosa. Tese de Doutorado. Disponível em < http://www.locus.ufv.br/handle/123456789/1456> Acesso em 19 set. 2012.

Halpern M. 1987. The organization and function of the vomeronasal system. Annu. Rev. Neurosci. 10(1):325-362.<http://dx.doi.org/10.1146/annurev ne.10.030187.001545><PMid:3032065>

Holy T.E., Dulac C. \& Meister M. 2000. Responses of vomeronasal neurons to natural stimuli. Science 289(5484):1569-1572.<http://dx.doi.org/10.1126/ science.289.5484.1569><PMid:10968796>

Keverne E.B. 1999. The vomeronasal organ. Science 286(5440):716-720. <http://dx.doi.org/10.1126/science.286.5440.716><PMid:10531049>

Lange R.R. \& Schmidt E.M.S. 2007. Rodentia: roedores silvestres (capivara, cutia, paca, ouriço), p.475-491. In: Cubas Z.S., Silva J.C.R. \& Catão-Dias J.A (Eds), Tratado de Animais Selvagens: medicina veterinária. Roca, São Paulo.

Leal L.M., de Freitas H.M., Sasahara T.H.C. \& Machado M.R.F. 2014. The hindlimb arterial vessels in lowland paca (Cuniculus paca, Linnaeus 1766). Anat. Histol. Embryol. 45(2):154-157. <http://dx.doi.org/10.1111/ahe.12160> $<$ PMid:25370292>

Lindsay F.E.F., Clayton H.M. \& Pirie M.E.S. 1978. The vomeronasal organ of the horse and donkey. J. Anat. 137:655.

Matamoros Y. 1982. Notas sobre la biologia del tepezcuinte, Cuniculus paca, Brisson, (Rodentia: Dasyproctidae) en cautiverio. Brenesia, San Jose 19/20:71-82.

Meredith M. 1994. Chronic recording of vomeronasal pump activation in awake behaving hamsters. Physiol. Behav. 56(2):345-354.<http://dx.doi org/10.1016/0031-9384(94)90205-4> <PMid:7938248>

Meredith M., Marques D.M., O'Connell R.J. \& Stern F.L. 1980. Vomeronasal pump: significance for male hamster sexual behavior. Science 207(4436):12241226. <http://dx.doi.org/10.1126/science.7355286><PMid:7355286>
Mockrin M.H., Bennet E.L. \& Labruna D.T. 2005. Wildlife Farming: a viable alternative to hunting in tropical forests? WCS Working Paper 23th ed, Wildlife Conservation Society, New York. 32p.

Mondolfi E. 1972. La laca o paca. Def. de la Nat. 2(5):4-16.

Mucignat-Caretta C. 2010. The rodent accessory olfactory system. J. Comp. Physiol. A 196(10):767-777. <http://dx.doi.org/10.1007/s00359-0100555-z> <PMid:20607541>

Organización de las Naciones Unidas para la Agricultura y la Alimentación 1995. La paca silvestre: la domesticación y cria de la paca (Agouti paca). Guia FAO Conservacion 26(3):9. Disponível em <http://www.fao.org/ docrep/006/V4940S/V4940s04.htm> Acesso 18 jun. 2008.

Pachaly J.R., Acco A., Lange R.R., Nogueira T.M.R., Nogueira M.F. \& Ciffoni E.M.G. 2001. Order Rodentia (Rodents), p.225-237. In: Fowler M.E. \& Cubas Z.S. (Eds), Biology, Medicine, and Surgery of South American Wild Animals. State University Press, Iowa.

Park C., Ahn M., Lee J.Y., Lee S., Yun Y.M., Lim Y.K., Taniguchi K. \& Shin T.A. 2014. Morphological study of the vomeronasal organ and the accessory olfactory bulb in the Korean roe deer, Capreolus pygargus. Acta Histochem. 116(1):258-264. <http://dx.doi.org/10.1016/j.acthis.2013.08.003> <PMid:24055195>

Queirolo D., Vieira E., Emmons L. \& Samudio R. 2008. Cuniculus paca. IUCN Red List of Threatened Species. Disponível em <www.iucnredlist.org> Acesso em 28 mar. 2010.

Rocha P.L.B. 1995. Proechimys yonenagae, a new species of spiny rat (Rodentia: Echimyidae) from fossil sand dunes in the Brazilian Caatinga. Mammalia 59(4):537-549. <http://dx.doi.org/10.1515/mamm.1995.59.4.537>

Roslinski D.L., Bhatnagar K.P., Burrows A.M. \& Smith T.D. 2000. Comparative morphology and histochemistry of glands associated with the vomeronasal organ in humans, mouse lemurs, and voles. Anat. Rec., Hoboken, 260(1):92101. <http://dx.doi.org/10.1002/1097-0185(20000901)260:1<92::AIDAR100>3.0.CO;2-\#><PMid:10967540>

Salazar I., Quinteiro P.S. \& Cifuentes J.M. 1995. Comparative anatomy of the vomeronasal cartilage in mammals: mink, cat, dog, pig, cow and horse. Ann. Anat. 177(5):475-481. <http://dx.doi.org/10.1016/S09409602(11)80156-1><PMid:7645743>

Salazar I., Cifuentes J.M. \& Sánchez-Quinteiro P. 2013. Morphological and immunohistochemical features of the vomeronasal system in dogs. Anat. Rec. 296(1):146-155.<http://dx.doi.org/10.1002/ar.22617><PMid:23161754>

Salazar I., Sanchez Quinteiro P., Cifuentes J.M. \& Garcia Caballero T. 1996. The vomeronasal organ of the cat. J. Anat. 188(Pt 2):445-454. <PMid:8621344>

Salazar I., Sánchez-Quinteiro P., Lombardero M. \& Cifuentes J.M. 2000. A descriptive and comparative lectin histochemical study of the vomeronasal system in pigs and sheep. J. Anat. 196(Pt 1):15-22. <http://dx.doi. org/10.1046/j.1469-7580.2000.19610015.x><PMid:10697284>

Salazar I., Sánchez Quinteiro P., Lombardero M., Aleman N. \& Fernández de Trocóniz P. 2004. The prenatal maturity of the accessory olfactory bulb in pigs. Chem. Senses 29(1):3-11. <http://dx.doi.org/10.1093/chemse/ bjh001> <PMid:14752035>

Salazar I., Sánchez-Quinteiro P., Alemañ N., Cifuentes J.M. \& FernándezTrocóniz P. 2007. Diversity of the vomeronasal system in mammals: the singularities of the sheep model. Microsc. Res. Technique 70(8):752-762. <http://dx.doi.org/10.1002/jemt.20461> <PMid:17394199>

Santos B.F. 2006. Modelo animal, p.23-24. In: Andrade A., Pinto S.C. \& Oliveira R.S. (Eds), Animais de Laboratório: criação e experimentação. Fiocruz, Rio de Janeiro.

Taniguchi K. \& Mochizuki K. 1982. Morphological studies on the vomeronasal organ in the golden hamster. Jpn. J. Vet. Sci. 44(3):419-426. <http://dx.doi. org/10.1292/jvms1939.44.419><PMid:7132015> 
Taniguchi K. \& Mochizuki K. 1983. Comparative morphological studies on the vomeronasal organ in rats, mice and rabbits. Jpn. J. Vet. Sci. 45(1):67-76. <http://dx.doi.org/10.1292/jvms1939.45.67><PMid:6865175>

Vaccarezza O.L., Sepich L.N. \& Tramezzani J.H. 1981. The vomeronasal organ of the rat. J. Anat. 132(Pt 2):167-185. <PMid:7275797>
VavukJ.W. 2012. A importância do estudo da anatomia humana para o estudante da área de saúde. Anatomista, São Paulo, 2(3):4-32. Disponível em <http:// www.sbanatomia.org.br/arquivos/a3v2.pdf> Acesso em 10 out. 2012.

Weiler E., Mcculloch M.A. \& Farbman A.I. 1999. Proliferation in the vomeronasal organ of the rat during postnatal development. Eur. J. Neurosci. 11(2):700-711. <http://dx.doi.org/10.1046/j.1460-9568.1999.00476.x><PMid:10051771> 